\title{
Flow and Heat Transfer Analysis of a Nanofluid along a Vertical Flat Plate in Presence of Thermal Radiation Using Similarity Transformation Method.
}

\author{
*Dr. K. Hemalatha ${ }^{1}$, A. Krishna keerthi ${ }^{2}$, ${ }^{*}$ Dr. G. SambasivaRao ${ }^{3}$.

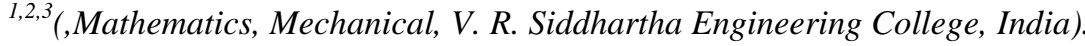

\begin{abstract}
In the present work effects of viscous dissipation and thermal radiationon convective heat transfer in nanofluid flow over a stretching sheet under the influence of applied magnetic field was analyzed. Three types of nanofluids, namely $\mathrm{Cu}$-water, $\mathrm{Al}_{2} \mathrm{O}_{3}$-water and $\mathrm{TiO}_{2}$-water were considered. A similarity transformation was used to obtain a system of non-linear ordinary differential equation which was then solved numerically using MATLAB "bvp4c" function. Numerical results were obtained for Local Nusselt number as well as velocity and temperature profiles for selected values of parameters such as nanoparticle volume fraction $\Phi$, Eckert number $E_{C}$, Magnetic parameter $M$ and thermal radiation parameter $N_{R}$ for fixed value of Prandtl number $P r=6.2$ (corresponding to water).It was shown that the Cu-water nanofluid exhibits higher heat transfer rate as compared to $\mathrm{Al}_{2} \mathrm{O}_{3}$-water and $\mathrm{TiO}_{2}$-water.
\end{abstract}

Keywords:Nanofluid flow, Heat transfer, Stretching sheet, Similarity Transformation,Thermal Radiation Parameter.

\section{Introduction:}

The problem of viscous flow and heat transfer over a stretching sheet has many important industrial applications, for example in metallurgical processes, drawing of continuous filaments through quiescent fluids, annealing and tinning of copper wires, glass blowing, manufacturing of plastic and rubber sheets, crystal growing, continuous cooling and fiber spinningetc. During the manufacture of these sheets, the melt issues from a slit and is subsequently stretched to achieve the desired thickness. The final product with the desired characteristics strictly depends upon the stretching rate, the rate of cooling in the process, and the process of stretching. In view of these applications, Choi[1] analyzed concept of high thermal conductivity of nanofluids which has demonstrated by applying Hamilton and Crosser (1962) model to copper nanoparticles in water. Chamka[2] analyzed problem of free convection from a vertical stretching surface in presence of magnetic, heat generation/ absorption and wall suction/injection effects by finite difference method(FDM). Considering twodimensional enclosure heat transfer enhancement is studied numerically by Khanfer et al.[3]. He found that presence of nanoparticles in the fluid is found to alter the structure of fluid flow. Salem et al[4],Oztop[5] , Hamad and Bashir[6] , Nandeppanvar[8] studied flow and heat transfer characteristics of a viscous fluid over a non-linearly stretching sheet in the presence of non-uniform heat source and variable wall temperature by shooting technique with a fourth order Runge-kutta method to obtain solution of boundary value problem.

A nanofluid is a new class of heat transfer fluids that contain a base fluid and nanoparticles. The use of additives is a technique applied to enhance the heat transfer performance of base fluids. The thermal conductivity of ordinary heat transfer fluids is not adequate to meet today's cooling rate requirements. Nanofluids have been shown to increase the thermal conductivity and convective heat transfer performance of the base liquids. Nanofluids are suspensions of submicronic solid particles (nanoparticles) in common fluids. The term was coined by Choi [1]. Rana and Bhargava [9] studied heat transfer enhancement by Galerkin Finite Element Method(FEM) for spherical shaped nanoparticles with volume fraction up to $4 \%$ with associated boundary conditions. They found that different nanoparticle size can also be used to control the motion and temperature of fluid and small sized nanoparticle has found to be high Nusselt number as compared to large sized.Noghrehabadi[10] analyzed heat transfer enhancement of water in presence of silicon-oxide over an isothermal stretching sheet. They used similarity transformation which was then solved by numerical method. Aman, Ishak, Pop [11] analyzed features of the flow and heat transfer characteristics for different values of the governing parameters numerically by shooting method. He found that for the opposing flow, the dual solutions exist for a certain range of the buoyancy parameter, whereas for the assisting flow, the solution is unique.Kameswaran [14] investigated heat and mass transfer in copper-water and silver-water nanofluids over stretching sheet subjected to viscous dissipation and chemical reaction effects. He solved differential equations numerically by MATLAB "bvp4c" function. He showed that copper-water nanofluid exhibits higher wall heat and mass transfer rates compared to silver-water nanofluid.Nadeem [16] presented boundary layer flow of a nanofluid over an exponential stretching surface. Similarity Transformation is used which was then solved 
analytically by Homotopy analysis method. Hady[18] investigated flow and heat transfer characteristics of viscous nanofluid over a non-linearly stretching sheet in presence of thermal radiation by using shooting technique with fourth order Runge-Kutta scheme. He considered steady incompressible, laminar, twodimensional boundary layer flow of a viscous nanofluid past a flat sheet for three different types of nanoparticles namely copper, alumina and titanium-oxide with water as base fluid. He showed that titaniumoxide nano-particles proved to have the highest cooling performance for this problem. Zaimi, Ishak, and Pop [19] investigatedthe steady two-dimensional boundarylayer flow of a nanofluid over a shrinking sheet with thermal radiation and suction effects by using a shooting method for three different types of nanoparticles, namely, copper $(\mathrm{Cu})$, alumina $\left(\mathrm{Al}_{2} \mathrm{O}_{3}\right)$, and Titanium $\left(\mathrm{TiO}_{2}\right)$. It is also found that $\mathrm{Cu}$-water nanofluid has the highest skin friction coefficient and the localNusselt number compared to $\mathrm{TiO}_{2}$-water and $\mathrm{Al}_{2} \mathrm{O}_{3}$-water nanofluids. Meraj Mustafa [20] studied flow of nanofluid in the region of stagnation-point towards an exponential stretching sheet numerically by MATLAB "bvp4c" function. They observed that increase in strengths of Brownian motion and thermophoretic effects causes an increase in temperature and boundary layer thickness. Malvandi[21] deals with stagnation point flow of nanofluid towards an exponential stretching sheet with non-uniform heat generation/absorption by HAM method. They found that increasing in stretching parameter leads to a gentle rise in both heat transfer and concentration rates. Rajesh Sharma, Ishak, and Pop [23] studiedthe boundary layer flow and heat transfer of a nanofluid over a stretching sheet by using Finite Element Method (FEM). He found that to achieve a high heat transfer rate, less slip on the fluid-solid interface is desired.

The study of magnetic field effects has important applications in physics, chemistry and engineering. In recent years there havebeen several applications in the polymer industry and metallurgy. The metallurgical applications include the cooling of continuous strips or filaments in, for example, the process of drawing, annealing,and tinning of copper wires. In all these cases, the properties of the final product depend to a great extent on the rate of cooling. Drawing such strips in an electrically conducting fluid subject to a magnetic field can control the rate of cooling and stretching thereby improving the desired characteristics of the final product. Fang Tie-Gang[7] solved magneto hydrodynamic (MHD) flow under slip condition by analytical method. He considered a steady two-dimensional laminar flow over a continuously shrinking sheet in a quiescent electrically conducting fluid. He showed that the velocity slip at the shrinking sheet can greatly affect the velocity distribution and drag forces on the wall. Uddin[17] studied free convective MHD laminar incompressible boundary layer flow of an electrically conducting nanofluid past a vertical plate. He assumed that surface of the plate is subjected to Newtonian heating boundary condition. He concluded that magnetic field significantly controls the flow, heat and mass transfer characteristics. Javad [12] presented heat transfer characteristics of viscous flow over a non-linearly stretching sheet in presence of viscous dissipation by fourth-order Runge-kutta integration scheme accompanied by shooting technique with Newton-Raphson iteration method.

Noghrehabadi, Pourrajab, Ghalambaz [13] analyzeddevelopment of the slip effects on the boundary layer flow and heat transfer over a stretching surface in the presence of nanoparticle fractions by numerical method. He found that with an increase in velocity slip factor the momentum boundary layer thickness and thermal boundary layer thickness decreased and increased respectively and with an increase of thermophoresis number the effect of velocity slip parameter on reduced Nusselt number and reduced Sherwood number increase and decrease respectively. Prasad[15] studied heat transfer of viscous fluid over shrinking permeable sheet with a power law velocity in thermally stratified medium by Keller- Box method. He considered laminar twodimensional viscous flow in a quiescent fluid. He assumed that fluid is incompressible. Mustafa [20] studied flow of nanofluid in the region of stagnation-point towards an exponential stretching sheet numerically by MATLAB "bvp4c" function. They considered effects of Brownian motion and Thermophoresis. They observed that increase in strengths of Brownian motion and thermophoretic effects causes an increase in temperature and boundary layer thickness. Poornima et al. [22] investigate boundary layer flow of a radiating nanofluid along a non-linearly stretching sheet in the presence of transverse magnetic field by Runge-kutta fourth order method along with shooting technique. They consider the effects of Brownian motion and Thermophoresis. They concluded that heat transfer rate rises with a rise in the magnetic parameter or radiation parameter or thermophoretic parameter or Brownian motion parameter and it falls with an increase in solutal buoyancy parameter or Lewis number.

\section{Mathematical Formulation:}

Let us consider the two-dimensional steady laminar flow of an incompressible nanofluid over a stretching sheet. The origin of the system is located at the slit from which the sheet is drawn. In this coordinate frame the $\mathrm{x}$-axis is taken along the direction of the continuous stretching surface. The $\mathrm{y}$-axis is measured normal to the surface of the sheet. It is assumed that the induced magnetic field is negligible in comparison to the applied magnetic field. The fluid is a water based nanofluid containing three differenttypes of nanoparticles; copper, aluminum and titanium oxide nanoparticles. It is assumed that the base fluid and the nanoparticles are in thermal equilibrium and no slip occurs between them. The thermo physical properties of the nanofluid are given 
in Table 1. With the above assumptions, the boundary layer equations governing the nanofluid flow, the heat fields canbe written in dimensional form as

$\frac{\partial \mathrm{u}}{\partial \mathrm{x}}+\frac{\partial \mathrm{v}}{\partial \mathrm{y}}=0$

$\mathrm{u} \frac{\partial \mathrm{u}}{\partial \mathrm{x}}+\mathrm{v} \frac{\partial \mathrm{u}}{\partial \mathrm{y}}=\frac{\mu_{\mathrm{nf}}}{\rho_{\mathrm{nf}}} \frac{\partial^{2} \mathrm{u}}{\partial \mathrm{y}^{2}}-\frac{\sigma \mathrm{B}_{0}^{2}}{\rho_{\mathrm{nf}} \mathrm{u}}$

$\mathrm{u} \frac{\partial \mathrm{T}}{\partial \mathrm{x}}+\mathrm{v} \frac{\partial \mathrm{T}}{\partial \mathrm{y}}=\alpha_{\mathrm{nf}} \frac{\partial^{2} \mathrm{~T}}{\partial \mathrm{y}^{2}}+\frac{\mu_{\mathrm{nf}}}{\left(\rho \mathrm{C}_{\mathrm{p}}\right)_{\mathrm{nf}}}\left(\frac{\partial \mathrm{u}}{\partial \mathrm{y}}\right)^{2}-\left(\frac{1}{\left(\rho \mathrm{C}_{\mathrm{p}}\right)_{\mathrm{nf}}}\left(\frac{\partial \mathrm{q}_{\mathrm{r}}}{\partial \mathrm{y}}\right)\right)$

\section{Thermo physical properties of water and copper, alumina and titanium oxide nanoparticles} (Table 1):

\begin{tabular}{|l|l|l|l|}
\hline & properties & & \\
\hline & $\rho(\mathrm{kg} / \mathrm{m})$ & $\mathrm{Cp}(\mathrm{J} / \mathrm{kg} \mathrm{k})$ & $\mathrm{K}(\mathrm{w} / \mathrm{mk})$ \\
\hline Pure water & 997.1 & 4179 & 0.613 \\
\hline $\mathrm{cu}$ & 8933 & 385 & 401 \\
\hline $\mathrm{Al}_{2} \mathrm{O}_{3}$ & 3970 & 765 & 40 \\
\hline $\mathrm{TiO}_{2}$ & 4250 & 686.2 & 8.9538 \\
\hline
\end{tabular}

Where $\mathrm{x}$ and $\mathrm{y}$ are Cartesian coordinates along the sheet and normal to it, $\mathrm{u}$ and $\mathrm{v}$ are velocity components of the nanofluid in $\mathrm{x}$ and $\mathrm{y}$ directions, respectively.

$\rho_{\mathrm{nf}}$ and $\mu_{\mathrm{nf}}$ are density and effective viscosity of the nanofluid, and $\alpha_{\mathrm{nf}}$ is thermal diffusivity.

\section{BOUNDARY CONDITIONS:}

The boundary conditions for "(1)-(3)" are assumed in the form:

$$
\mathrm{u}=\mathrm{u}_{\mathrm{w}}=\mathrm{bx}, \quad \mathrm{v}=0, \quad \mathrm{~T}=\mathrm{T}_{\mathrm{w}}=\mathrm{T}_{\infty}+\mathrm{A}\left(\frac{\mathrm{x}}{\mathrm{l}}\right)^{2} \text { at } \mathrm{y}=0,
$$

$\mathrm{u} \rightarrow 0, \mathrm{~T} \rightarrow \mathrm{T}_{\infty}$ as $\mathrm{y} \rightarrow \infty$

Where $\mathrm{A}$ and $\mathrm{b}$ are constants, $\mathrm{l}$ is characteristic length, $\mathrm{T}_{\infty}$ is the temperature of the fluid far from the sheet.

Effective dynamic viscosity of nanofluid is

$\mu_{\mathrm{nf}}=\frac{\mu_{\mathrm{f}}}{(1-\varnothing)^{2.5}}$

Where $\Phi$ is the solid volume fraction of nanoparticles. The effective density, $\rho_{\mathrm{nf}}$, thermal diffusivity $\alpha_{\mathrm{nf}}$, and the heat capacitance of the nanofluid is given by

$\alpha_{\mathrm{nf}}=\frac{\mathrm{k}_{\mathrm{nf}}}{\left(\rho \mathrm{C}_{\mathrm{p}}\right)_{\mathrm{nf}}}$

$$
\rho_{\mathrm{nf}}=(1-\emptyset) \rho_{\mathrm{f}}+\emptyset \rho_{\mathrm{s}}
$$

$\left(\rho \mathrm{C}_{\mathrm{p}}\right)_{\mathrm{nf}}=(1-\emptyset)\left(\rho \mathrm{C}_{\mathrm{p}}\right)_{\mathrm{f}}+\emptyset\left(\rho \mathrm{C}_{\mathrm{p}}\right)_{\mathrm{s}}$

Garnett model

$$
\mathrm{k}_{\mathrm{nf}}=\frac{\mathrm{k}_{\mathrm{f}}\left[\mathrm{k}_{\mathrm{s}}+2 \mathrm{k}_{\mathrm{f}}-2 \emptyset\left(\mathrm{k}_{\mathrm{f}}-\mathrm{k}_{\mathrm{s}}\right)\right]}{\left[\mathrm{k}_{\mathrm{s}}+2 \mathrm{k}_{\mathrm{f}}+\emptyset\left(\mathrm{k}_{\mathrm{f}}-\mathrm{k}_{\mathrm{s}}\right)\right]}
$$

In "(6)-(9)", the subscripts $\mathrm{nf}, \mathrm{f}$ and $\mathrm{s}$ denote thermophysical properties of nanofluid, base fluid and nano-solid particles, respectively. Using the Roseland expression for radiation, the radiative heat flux is simplified as:

$$
\mathrm{q}_{\mathrm{r}}=-\frac{4 \sigma^{*}}{3 \mathrm{k}^{*}}\left(\frac{\partial \mathrm{T}^{4}}{\partial \mathrm{y}}\right)
$$

Where $\sigma$ and $\mathrm{k}$ are stefan-boltzmann constant and mean absorption coefficient, respectively. We assume that temperature differences within the flow, such as the term $\mathrm{T}^{4}$ may be expressed as linear function of temperature. Hence expanding $\mathrm{T}^{4}$ in a Taylor series about a free stream temperature $\mathrm{T}_{\infty}$ and neglecting higher order terms, we get:

$\mathrm{T}^{4} \cong 4 \mathrm{~T}^{3}{ }_{\infty} \mathrm{T}-3 \mathrm{~T}^{4}{ }_{\infty}$

From "(3)" and in view of"(10) and (11)", it is seen that effect of radiation is to enhance thermal diffusivity. If we take

$\mathrm{N}_{\mathrm{R}}=\frac{\mathrm{k}_{\mathrm{nf}} \mathrm{k}^{*}}{\left[4 \sigma^{*} \mathrm{~T}_{\infty}^{3}\right]}$ As the radiation parameter, “(3)" becomes:

$\mathrm{u} \frac{\partial \mathrm{T}}{\partial \mathrm{x}}+\mathrm{v} \frac{\partial \mathrm{T}}{\partial \mathrm{y}}=\frac{\alpha_{\mathrm{nf}}}{\mathrm{k}_{0}} \frac{\partial^{2} \mathrm{~T}}{\partial \mathrm{y}^{2}}+\frac{\mu_{\mathrm{nf}}}{\left(\rho \mathrm{C}_{\mathrm{p}}\right)_{\mathrm{nf}}}\left(\frac{\partial \mathrm{u}}{\partial \mathrm{y}}\right)^{2}$ 


$$
\mathrm{k}_{0}=\frac{3 \mathrm{~N}_{\mathrm{R}}}{\left(3 \mathrm{~N}_{\mathrm{R}}+4\right)}
$$

The continuity equation (1) is satisfied by introducing a stream function $\psi(\mathrm{x}, \mathrm{y})$ such that $\mathrm{u}=\frac{\partial \varphi}{\partial \mathrm{y}}, \mathrm{v}=-\frac{\partial \varphi}{\partial \mathrm{x}}$

The following similarity variables are also introduced

$\mathrm{T}=\mathrm{T}_{\infty}+\left(\mathrm{T}_{\mathrm{w}}-\mathrm{T}_{\infty}\right) \mathrm{g}(\eta), \eta=-\left(\mathrm{bv}_{\mathrm{f}}\right)^{\frac{1}{2}} \mathrm{y}, \quad \varphi=\left(\mathrm{v}_{\mathrm{f}} \mathrm{b}\right)^{\frac{1}{2}} \mathrm{x}_{\mathrm{f}}$

$$
u=b f^{\prime}(\eta), v=-\left(b v_{f}\right)^{\frac{1}{2}} f(\eta),
$$

Where $\eta$ is the similarity variable, $f(\eta)$ is the dimensionless stream function, $g(\eta)$ is the dimensionless temperature. On using “(5)”, (6)”, "(7)”,"“(8)”,"“(9)” and "(14)”, "(2)-(4)” transform into the following two-point boundary value problem:

$$
\begin{gathered}
f^{\prime \prime \prime}-\emptyset_{1}\left[f^{\prime 2}-f^{\prime \prime}+\frac{1}{\emptyset_{2}} M f^{\prime}\right]=0 \\
g^{\prime \prime}-\operatorname{Pr}\left(\frac{k_{f}}{k_{n f}}\right) \emptyset_{3} k_{0}\left[2 f^{\prime} g-f^{\prime}-\frac{1}{\emptyset_{4}} E_{C}\left(f^{\prime \prime}\right)^{2}\right] \\
f(0)=0, f^{\prime}(0)=1, f^{\prime}(\infty) \rightarrow 0, \\
g(0)=1, g(\infty) \rightarrow 0
\end{gathered}
$$

The non-dimensional constants appearing in "(15)-(18)" are the magnetic parameter M, prandtl number $\mathrm{Pr}$, Eckert number $\mathrm{E}_{\mathrm{C}}$. They are respectively defined as

Where

$$
M=\frac{\sigma B_{0}{ }^{2}}{\rho_{f} b}, \quad \operatorname{Pr}=\frac{v_{f}\left(\rho C_{p}\right)_{f}}{k_{f}}, \quad E_{C}=\frac{u_{w}{ }^{2}}{\left(C_{p}\right)_{f}}\left(T_{w}-T_{\infty}\right)
$$

$$
\begin{gathered}
\emptyset_{1}=(1-\emptyset)^{2.5}\left[1-\emptyset+\emptyset\left(\frac{\rho_{\mathrm{s}}}{\rho_{\mathrm{f}}}\right)\right], \\
\emptyset_{2}=1-\emptyset+\emptyset\left(\frac{\rho_{\mathrm{s}}}{\rho_{\mathrm{f}}}\right), \\
\emptyset_{3}=1-\emptyset+\emptyset\left(\frac{\left(\rho C_{\mathrm{p}}\right)_{\mathrm{s}}}{\left(\rho \mathrm{C}_{\mathrm{p}}\right)_{\mathrm{f}}}\right) \\
\emptyset_{4}=(1-\emptyset)^{2.5}\left[1-\emptyset+\emptyset\left(\frac{\left(\rho \mathrm{C}_{\mathrm{p}}\right)_{\mathrm{s}}}{\left(\rho \mathrm{C}_{\mathrm{p}}\right)_{\mathrm{f}}}\right)\right]
\end{gathered}
$$

\section{HeatTransfer Coefficients:}

The shearing stress at the surface of the wall $\tau_{\mathrm{w}}$ is given by

$\tau_{\mathrm{w}}=-\mu_{\mathrm{nf}}\left[\frac{\partial \mathrm{u}}{\partial \mathrm{y}}\right]_{\mathrm{y}=0}=-\frac{1}{(1-\emptyset)^{2.5}} \rho_{\mathrm{f}}\left(\sqrt{\mathrm{v}_{\mathrm{f}} \mathrm{b}^{3}}\right) \mathrm{xf}^{\prime \prime}(0)$,

Where $\mu_{\mathrm{nf}}$ is coefficient of viscosity.

The heat transfer rate at the surface flux at the wall is given by

$\mathrm{q}_{\mathrm{w}}=-\mathrm{k}_{\mathrm{nf}}\left[\frac{\partial \mathrm{T}}{\partial \mathrm{y}}\right]_{\mathrm{y}=0}=-\mathrm{k}_{\mathrm{nf}} \mathrm{A}\left(\frac{\mathrm{x}}{\mathrm{l}}\right)^{2} \sqrt{\frac{\mathrm{b}}{\mathrm{v}_{\mathrm{f}}}} \mathrm{g}^{\prime}(0)$,

Where $\mathrm{k}_{\mathrm{nf}}$ is the thermal conductivity of nanofluid. The Nusselt number is defined as

$$
\mathrm{Nu}_{\mathrm{x}}=\left(\frac{\mathrm{x}}{\mathrm{k}_{\mathrm{f}}}\right)\left(\frac{\mathrm{q}_{\mathrm{w}}}{\left(\mathrm{T}_{\mathrm{w}}-\mathrm{T}_{\infty}\right)}\right)
$$

Using "(21)" in " $(22)$ ", the dimensionless wall heat transfer rate is obtained as

$\left(\frac{\mathrm{Nu}_{\mathrm{z}}}{\sqrt{\mathrm{Re}_{\mathrm{x}}}}\right)\left(\frac{\mathrm{k}_{\mathrm{f}}}{\mathrm{k}_{\mathrm{nf}}}\right)=-\mathrm{g}^{\prime}(0)\left(1+\frac{4 \mathrm{R}}{3}\right)$

In " (23)" $\operatorname{Re}_{\mathrm{x}}$ represents the local Reynolds number defined as

$$
\operatorname{Re}_{\mathrm{x}}=\frac{\mathrm{xu}_{\mathrm{w}}}{\mathrm{v}_{\mathrm{f}}}
$$

Table 2Comparison of $f^{\prime \prime}(0)$ for various values of $M$ and $\Phi$ when $\operatorname{Pr}=6.2$.

\begin{tabular}{|l|l|l|l|l|l|}
\hline $\mathbf{M}$ & $\mathbf{\Phi}$ & $\begin{array}{l}\text { Kameswaran } \\
\text { Cu-water }\end{array}$ & $\begin{array}{l}\text { Present } \\
\text { results } \\
\text { Cu-water }\end{array}$ & $\begin{array}{l}\mathbf{A l}_{\mathbf{2}} \mathbf{3}^{-} \\
\text {water }\end{array}$ & $\begin{array}{l}\mathbf{T i O}_{\mathbf{2}^{-}} \\
\text {water }\end{array}$ \\
\hline 0 & 0.05 & 1.10892 & 1.10891 & 1.00537 & 1.01150 \\
\hline & 0.1 & 1.17475 & 1.17475 & 0.99877 & 1.00951 \\
\hline & 0.15 & 1.20886 & 1.20886 & 0.98184 & 0.99603 \\
\hline & 0.2 & 1.21804 & 1.21804 & 0.95591 & 0.97258 \\
\hline 0.5 & 0.05 & 1.29210 & 1.29210 & 1.20441 & 1.20952 \\
\hline & 0.1 & 1.32825 & 1.32825 & 1.17548 & 1.18462 \\
\hline & 0.15 & 1.33955 & 1.33955 & 1.13889 & 1.15114 \\
\hline & 0.2 & 1.33036 & 1.33036 & 1.09544 & 1.110021 \\
\hline \hline
\end{tabular}


It can be seen from Table 2 that $\left(\mathbf{f}^{\prime \prime}(0)\right)$ increases with an increase in the nanoparticle volume fraction $\Phi$, and Magnetic Parameter $\mathrm{M}$, and the $\mathrm{Cu}$ nanoparticles are the highest skin friction, followed by $\mathrm{TiO}_{2}$ and $\mathrm{Al}_{2} \mathrm{O}_{3}$. Increasing values of Magnetic effect $\mathrm{M}$ results in a considerable opposition to the flow due to a Lorenz drag force which enhances the values of skin friction coefficient.

\section{Results And Discussion:}

In order to get the physical insight into the flow problem, comprehensive numerical computations are conducted for various values of the parameters that describe the flow characteristics, and the results are illustrated graphically. The system of nonlinear ordinary differential " 15 " and " 16 " with the boundary conditions ("(18)") are solved by using MATLAB R2010a "bvp4c" solver. The physical quantities of interest here is Nusselt number $\mathrm{Nu}_{x}$, which are obtained and given in" $(23)$ ". The distributions of the velocity $\mathrm{f}^{\prime}(\eta)$, the temperature $\mathrm{g}(\eta)$ from "(15) and (16)", the Nusselt number for different types of nanofluids are shown in Figures 1, 2, 3, 4, 5, 6 and 7 respectively.3, 4, 5, 6 and 7 respectively.
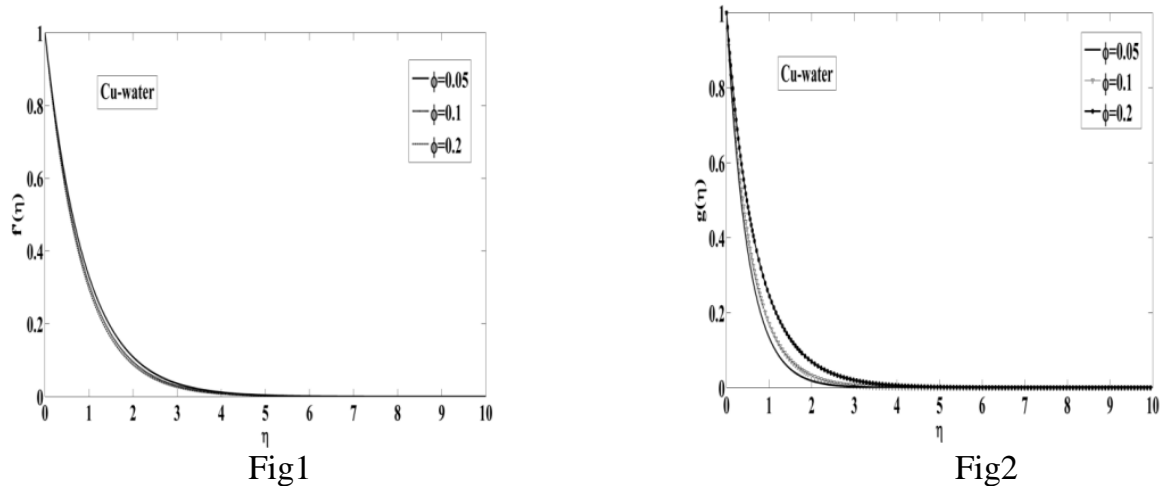

Fig.1 Effect of $\Phi$ on velocity distribution $f^{\prime}(\eta)$ for $E_{C}=0.1, \operatorname{Pr}=6.2, N_{R}=1, M=0$.

Fig. 2 Effect of $\Phi$ on Temperature distributiong $(\eta)$ for $E_{C}=0.1, \operatorname{Pr}=6.2, N_{R}=1, M=0$.

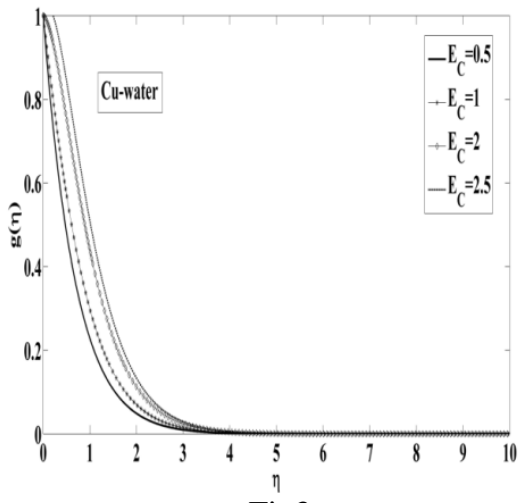

Fig3

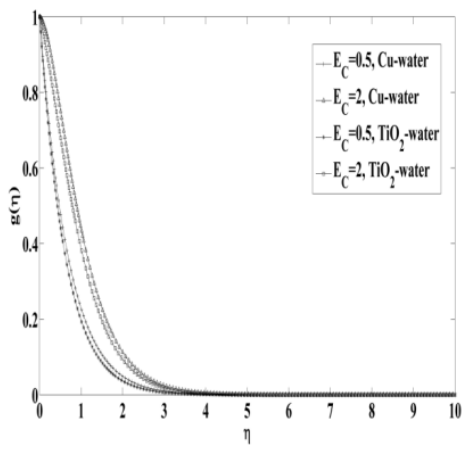

Fig 4

Fig. 3 Effect of $E_{C}$ on temperature profile $g(\eta)$ for $E_{C}=0.1, \operatorname{Pr}=6.2, N_{R}=1, M=0$.

Fig. 4 Effect of $E_{C}$ on temperature profilesg $(\eta)$ for $E_{C}=0.1, \operatorname{Pr}=6.2, N_{R}=1, M=0$.

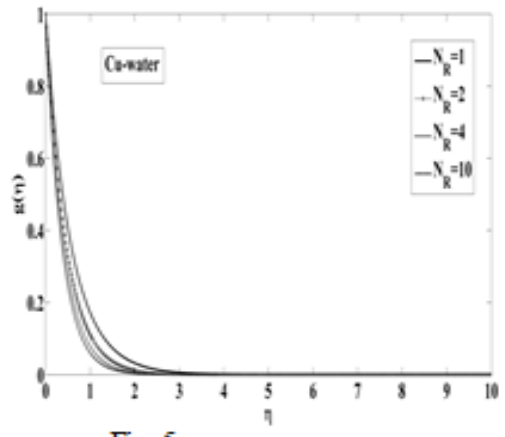

Fig 5

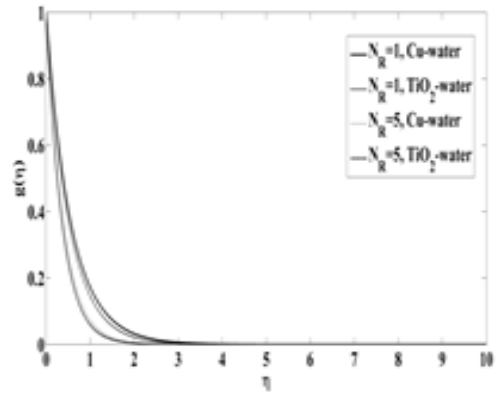

Fig 6 
Fig.5 Effect of $\mathrm{N}_{\mathrm{R}}$ on temperature profiles $\mathrm{g}(\eta)$ for $\mathrm{E}_{\mathrm{C}}=0.1, \operatorname{Pr}=6.2, \Phi=0.1, \mathrm{M}=0$.

Fig.6 Effect of $\mathrm{N}_{\mathrm{R}}$ on temperatureprofiles $\mathrm{g}(\eta)$ for $\mathrm{E}_{\mathrm{C}}=0.1, \operatorname{Pr}=6.2, \Phi=0.1, \mathrm{M}=0$.

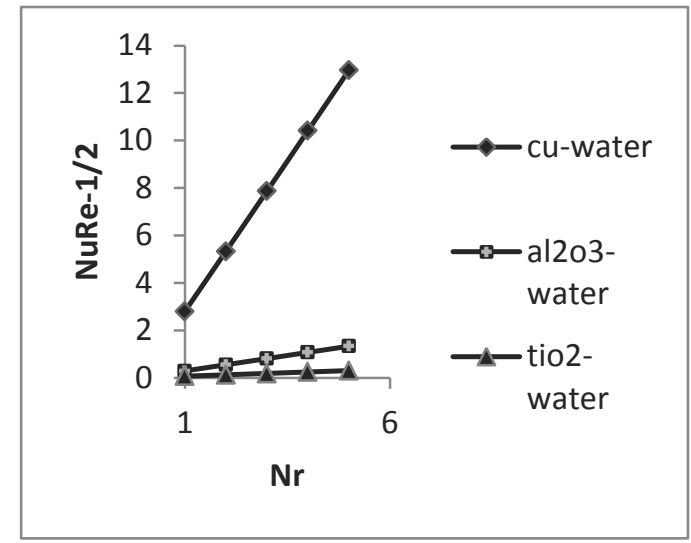

Fig.7 Effect of $\mathrm{N}_{\mathrm{R}}$ on Nusselt number $\mathrm{Nu}$ for $\mathrm{E}_{\mathrm{C}}=0.1, \operatorname{Pr}=6.2, \Phi=0.1, \mathrm{M}=0$.

\section{Stretching sheet results.}

We considered three different types of nanoparticles, namely, copper $(\mathrm{Cu})$, alumina $\left(\mathrm{Al}_{2} \mathrm{O}_{3}\right)$, and titanium oxide $\left(\mathrm{TiO}_{2}\right)$, with water as the base fluid. Table 1 shows the thermo-physical properties of water and the elements $\mathrm{Cu}, \mathrm{Al}_{2} \mathrm{O}_{3}$, and $\mathrm{TiO}_{2}$. The Prandtl number of the base fluid (water) is kept constant at 6.2. In order to verify the accuracy of the present method, we have compared our results with those of Kameswaran [14] for the rate of heat transfer - $g^{\prime}(0)$. Table 2 depicts the skin friction at the surface - $f^{\prime \prime}(0)$ for various values of Magnetic parameter $M$ and nanoparticle volume fraction $\Phi$ with $\operatorname{Pr}=6.2$,

Fig.7 Effect of $\mathrm{N}_{\mathrm{R}}$ on Nusselt number $\mathrm{Nu}$ for

$\mathrm{E}_{\mathrm{C}}=0.1, \operatorname{Pr}=6.2, \Phi=0.1, \mathrm{M}=0$.

$E_{C}=0.1$, and $N_{R}=1$ for different types of nanoparticles with base fluid as water. It can be seen from Table 2 that $\left(\mathbf{f}^{\prime \prime}(0)\right)$ increases with an increase in the nanoparticle volume fraction $\Phi$, and Magnetic Parameter $\mathrm{M}$. The $\mathrm{Cu}$ nanoparticles have highest skin friction, when compared to $\mathrm{TiO}_{2}$ and $\mathrm{Al}_{2} \mathrm{O}_{3}$. Increasing values of Magnetic effect $M$ results in a considerable opposition to the flow due to a Lorenz drag force which enhances the values of skin friction coefficient.

Figs 1 and 2 illustrate the effect of nanoparticle volume fraction $\phi$ on the nanofluid velocity and temperature profiles, respectivelyin the case of $\mathrm{Cu}$-water nanofluid. Fig 1 shows that in case of clear fluid $(\Phi=0)$, the value of skin friction coefficient is unity. It is also evident that, as the nanoparticles volume fraction increases, the nanofluid velocity decreases. Fig 2 shows that the temperature increases with the increase of nanoparticle volume fraction. These figures illustrate this agreement with the physical behavior. When the volume of nanoparticles increases, the thermal conductivity increases, and then the thermal boundary layer thickness increases.Figs 3 and 4 depict the effect of Eckert number $E_{C}$ on temperature profile $g(\eta)$ for cu-water and for different nano-particles, respectively. Fig 3illustrates that in the case of $\mathrm{Cu}$-water nanofluid temperature increases with an increase in $\mathrm{E}_{\mathrm{C}}$. Furthermore, Fig 4illustrates that the same nature is observed for $\mathrm{Al}_{2} \mathrm{O}_{3}$ and $\mathrm{TiO}_{2}$ which is clear from the fig 4 . The reason for being negative of $\mathrm{g}$ in a specific domain is the presence of velocity gradient outside the thermal boundary layer. These negative values by considering larger Eckert number are more significant. As soon as velocity gradient is removed (at the end of velocity boundary layer) the $\mathrm{g}$ reaches zero again. Figs 5 and 6depict the effect of thermal radiation parameter $\mathrm{N}_{\mathrm{R}}$ for $\mathrm{Cu}$-Water and for different nano-particles on temperature profile $\mathrm{g}(\eta)$, respectively. It is clear from the figure that temperature distribution decreases with an increase in $\mathrm{N}_{\mathrm{R}}$, thus leading to higher heat transfer rate between the nanofluids and the surface. Thus larger values of $\mathrm{N}_{R}$ show a dominance of the thermal radiation over conduction. Consequently larger values of $\mathrm{N}_{\mathrm{R}}$ are indicative of larger amount of radiative heat energy being poured into the system, causing a rise in $g(\eta)$. Fig 7 illustrate the effect of Thermal radiation parameter $N_{R}$ on the Nusselt number, in the case of different nanoparticles. It is clear that, as the thermal radiation parameter increases, the Nusselt number increases. $\mathrm{Cu}$-water nanofluid has the highest local Nusselt number when compared with $\mathrm{TiO}_{2^{-}}$ water and $\mathrm{Al}_{2} \mathrm{O}_{3}$-water nanofluids. The presence of nanoparticles in the base fluid significantly changes the heat transfer characteristics. The Nusselt number is a multiplication of temperature gradient and the thermal conductivity ratio (conductivity of the nanofluid to the conductivity of the base fluid). Since the reduction in temperature gradient due to the presence of nanoparticles is much smaller than thermal conductivity ratio therefore an enhancement in Nusselt number is taken place by increasing the volume fraction of nanoparticles. 


\section{Conclusions:}

The problem of boundary-layer flow and heat transfer in a viscous nanofluid over a nonlinearly stretched surface in the presence of thermal radiation using the Roseland approximation for the radiative heat flux was analyzed. The governing partial differential equations were converted to ordinary differential equations by using a suitable similarity transformation and were then solved numerically by MATLAB R2010a "bvp4c" function. The effects of the solid volume fraction $\phi$, thermal radiation parameter $N_{\mathbf{R}}$, Magnetic effect $M$, and the viscous dissipation parameter $\mathrm{E}_{\mathrm{C}}$ on the flow and heat transfer characteristics are determined for three kinds of nanofluids: copper, alumina, and titanium oxide. The type of nanofluid is a key factor for heat transfer enhancement. The increase of the solid volume fraction $\phi$ and the Magnetic parameter M leads to the decrease of dimensionless surface velocity in the case of $\mathrm{Cu}$-Water; this yields an increase in the skin friction at the surface. Increasing magnetic field strength leads to decrease the rate of heat transfer rate. Magnetic field significantly controls the flow, heat transfer characteristics. An increment in Eckert number $\mathrm{E}_{\mathrm{C}}$ yields an increment in the nanofluid's temperature; this leads to a rapid reduction in the heat transfer rates. An increase in the thermal radiation parameter $N_{R}$ yields a decrease in the nanofluid's temperature, which leads to an increase in the heat transfer rates and the presence of radiation radiates the heat energy away from the fluid. It is the nanofluids property to enhance thermal conductivity. The difference in heat transfer, using different nanofluids, increases with increasing the value of thermal radiation parameter $\mathrm{N}_{R}$. It is shown that inclusion of nanoparticles into the base fluid of this problem is capable to change the flow pattern. The study of nanofluids is still at its stage so that it seems difficult to have a precise idea on the way the use of nanoparticles to understand the flow and heat transfer characteristics of nanofluids and identify new and unique applications for these fluids. Cu-water nanofluidhas the highest local Nusselt number compared with $\mathrm{TiO}_{2}$-water and $\mathrm{Al}_{2} \mathrm{O}_{3}$-water nanofluids.

\section{References:}

[1]. Stephen.U.S.Choi and J.A,Eastman.Enhancing thermal conductivity of fluids with NanoparticlesArgonne,\#W-31-109-ENG38(1995).

[2]. Ali.J.Chamka,Hydro magnetic three-dimensional free convection on a vertical stretching Surfacewith heat generation or absorption, 20,84-92(1999).

[3]. Khalilkhanfer,Kambizvafai,Marilyn light stone,Buoyancy-driven two-dimensional heat Transfer enhancement in a two-dimensional enclosure utilizing nanofluids,International Journal of heat and mass transfer 46, 3639-3653(2003).

[4]. Ahmed M Salem, Mohamed Abd EI-Aziz,Effect of hall currents and chemical reaction on Hydromagnetic flow of a stretching vertical surface with internal heat generation/ Absorption, 32, 1236-1254(2008).

[5]. HakanF. Oztop, Eiyad Abu-Nada.,2008,Numerical study of natural convection in partially Heated rectangular enclosures filled with nanofluids. International journal of heat and fluid Flow, 29, 1326-1336(2008).

[6]. M. A. A. Hamad and M. A. Bashir, Boundary-Layer flow and Heat Transfer of a power Law Non-Newtonian Nanofluid over a vertical Stretching Sheet, 172-178(2009).

[7]. Fang tie-Gang, Zhang, Yao shan-shan, Slip magnetohydrodynamic viscous flow over a Permeableshrinking sheet,vol.27, No.12,124702(2010).

[8]. M. M. Nandeppanvar, K. Vajravelu, M. Subhas Abel,Heat Transfer over a nonlinearly Stretching sheet with non-uniform heat source and variable wall temperature, 54, 4960-4965(2011).

[9]. PuneetRana and R. Bhargava,Flow and Heat Transfer Analysis of a Nanofluid Along a Vertical Flat Plate with Non-Uniform Heating Using Fem: Effect of Nanoparticle Diameter, vol.1, no. 3, (2011).

[10]. A. Noghrehabadi, Mehdi Ghalambaz and Mohammad Ghalambaz,A TheoreticalInvestigation of SiO ${ }_{2}$-Water Nanofluid Heat Transfer Enhancement over an Isothermal Stretching sheet, vol. 2, No.9 (2011).

[11]. F. Aman, A. Ishak, I. Pop,Mixed Convection Boundary Layer Flow near stagnation point On Vertical surface with slip, 32(12), 1599-1606 (2011)

[12]. JavadAlinejad and SinaSamarbaksh,Viscous Flow over nonlinearly stretching Sheet With Effects of ViscousDissipation, vol587834(2012).

[13]. AminrezaNoghrehabadi, Rashid Pourrajab, Mohammad Ghalambaz,Effect of Partial Slip Boundary Condition on the Flow and Heat Transfer of Nanofluidspast Stretching Sheet Prescribed Constant Wall Temperature,International Journal of Thermal Sciences 54, 253e261 (2012).

[14]. P.K.Kameswaran, M. Narayana, P. Sibanda and P. V. S. N. Murthy,Hydromagnetic Nanofluid flow due to a stretching or shrinking sheet with viscous dissipation and Chemical reaction effects, International Journal of Heat and Mass Transfer, 7587-7595(2012).

[15]. K.V.Prasad, Flow and Heat Transfer at a Nonlinearly Shrinking Porous Sheet in a ThermallyStratified Medium,International Journal of Mathematical Archive-3(8), 3004-3015(2012).

[16]. S. Nadeem and Changhoon Lee, Boundary Layer Flow of Nanofluid over an Exponentially StretchingSurface (2012).

[17]. Mohammad J Uddin, Waqar A. Khan and Ahmed I. Ismail,MHD Free Convective Boundary Layer flow of a Nanofluid past a flat vertical Plate with Newtonian Heating Boundary Condition, vol. 7, issue 11, e49499 (2012).

[18]. Fekry M Hady, Fouad S Ibrahim, Sahar M Abdel-Gaied and Mohamed R Eid,Flow and Heat Transfer Characteristics of a Viscous Nanofluid over a Non-Linearly Stretching sheet In the Presence of Thermal Radiation, 1556-276X-7-229(2012).

[19]. KhairyZaimi, AnuarIshak, and Ioan Pop,Boundary Layer Flow and Heat Transfer past a Permeable Shrinking Sheet in a Nanofluid with Radiation Effect, Article ID 340354.1(2012).

[20]. Meraj Mustafa, Muhammad A. Farooq, Taswar Hayat, Ahmed Alsaedi,Numerical and Series Solutions for Stagnation-Point Flow of Nanofluid over an Exponentially Stretching Sheet, Vol. 8, Issue 5, e61859 (2013).

[21]. A. Malvandi, F. Hedayati, and G. Domairry,Stagnation Point Flow of a Nanofluid toward An Exponentially Stretching Sheet with nonuniform Heat Generation/ Absorption, Article ID 764827(2013).

[22]. T. Poornima and N. Bhaskar Reddy,Radiation effects on MHD Free Convective Boundary Layer Flow of Nanofluids over a Nonlinear Stretching sheet, 190-202(2013). 
[23]. Rajesh Sharma, AnuarIshak, and Ioan Pop,Partial Slip Flow and Heat Transfer Over a Stretching Sheet in a Nanofluid", Article ID 724547(2013).

[24]. EiyadAbu-Nada, Hakan F. Oztop,Effects of inclination angle on natural convection(a) In Enclosures filled with Cu-Water nanofluid “, International Journal of Heat and Fluid Flow.

[25]. Emily Pfautsch, Forced Convection in Nanofluids over a Flat Plate(2008). 